\title{
HISTÓRICO DA COMPOSIÇÃO DA VEGETAÇÃO ARBÓREA DO PARQUE DO IBIRAPUERA E SUA CONTRIBUIÇÃO PARA A CONSERVAÇÃO DA BIODIVERSIDADE
}

\author{
Yukie Kabashima'; Marcelo Leandro Feitosa Andrade²; Flávio B. Gandara ${ }^{3}$; \\ Fábio L. Tomas ${ }^{4}$; Jefferson L. Polizel ${ }^{5}$; Giuliana D. N. Velasco ${ }^{6}$; Luzia F. da Silva ${ }^{7}$; Angela D. \\ P. Dozzo ${ }^{8}$; Rogério G. Moura9; Demóstenes Ferreira da Silva Filho ${ }^{10}$
} (recebido em 03.04.2010 e aceito para publicação em 15.12.2011)

\section{RESUMO}

Os parques urbanos, além de importantes espaços de recreação, esportes, lazer, cultura e promover melhoria na qualidade de vida, apresentam potencial de contribuir para a biodiversidade regional. Objetivou-se discutir as modificações históricas da composição da vegetação arbórea do Parque Ibirapuera de São Paulo, SP; sua contribuição para a conservação da biodiversidade regional; e analisar as espécies arbóreas do Parque quanto ao risco de queda. Para isso, foi elaborado inventário por censo dos indivíduos arbóreos do Parque Ibirapuera. Historicamente as primeiras vegetações inseridas no Parque possuíam o papel de promover a drenagem da área com o uso de espécies arbóreas exóticas, como as do gênero Eucalyptus e Ligustrum, que hoje representam 16\% e 7,29\% das árvores, respectivamente. Estas representaram a maior porcentagem de espécies classificadas em risco de queda alto, 83,7\%. A inserção posterior de espécies nativas no Parque contribuiu

\footnotetext{
1. Arquiteta Urbanista, Mestre em Recursos Florestais - Escola Superior de Agricultura "Luiz de Queiroz", Universidade de São Paulo (ESALQ/USP). Email: yukie_kabashima@hotmail.com

2. Biólogo, Mestre em Ciências: Biologia na Agricultura e no Ambiente - Centro de Energia Nuclear na Agricultura, USP. Email: biomarcello@gmail.com

3. Engํㅡㄹ Agrônomo, Professor adjunto - ESALQ/USP. Email: fgandara@esalq.usp.br

4. Eng ${ }^{\circ}$ Agrônomo, Mestre em Recursos Florestais - ESALQ/USP. Email: fltomas@esalq.usp.br

5. Especialista em Geoprocessamento. Dr. em Geografia - USP Email: jlpolize@esalq.usp.br

${ }^{6}$. Eng ${ }^{\mathrm{a}}$ Agrônoma, Mestre em Agronomia, Dra. em Agronomia - ESALQ/USP. Email: gdnvelas@esalq.usp.br

. Agrônoma, Mestre em Fitotecnia, Dra. em Fitotecnia - ESALQ/USP. Email: Ifsilva68@hotmail.com

${ }^{8}$. Eng ${ }^{\circ}$ Florestal, Especialista em Gerenciamento Ambiental - ESALQ/USP. Email: angela@reservanatural.org.br

9. Eng ${ }^{\circ}$ Florestal, Mestre em Silvicultura e Manejo Florestal, Doutorando em Ecologia Aplicada - USP. Email: rgmoura@esalq.usp.br

10. Engํㅡㄹ Agrônomo, professor adjunto - ESALQ/USP, Departamento de Ciências Florestais, dfsilva@esalq.usp.br
}

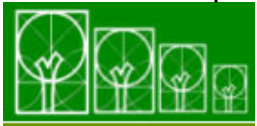

$\mathbf{S} \cdot \mathbf{B} \cdot \mathbf{A} \cdot \mathbf{U}$ Soc. Bras. de Arborização Urbana 
para o aumento da biodiversidade regional, atualmente apresentando 39,4\% de árvores nativas brasileiras. Os resultados indicam a necessidade da contínua diversificação de árvores e arbustos com espécies nativas, pois além de contribuir para a minimização de pragas e doenças vegetais, pela manutenção da diversidade e dos processos ecológicos na paisagem urbana, poderá prevenir fatores importantes que provocam a queda de árvores.

Palavras-chave: Parque Ibirapuera, silvicultura urbana, parque urbano, diversidade, risco de queda.

\section{HISTORICAL CHANGES IN IBIRAPUERA PARK'S ARBOREAL VEGETATION COMPOSITION AND ITS CONTRIBUTION FOR BIODIVERSITY CONSERVATION}

\section{ABSTRACT}

Urban parks, besides being important for recreation, sports, leisure, culture and promoting better quality of life, they can also represent a potential increase for regional biodiversity. The goals of this article were to discuss historical changes in the arboreal vegetation composition from the Ibirapuera Park in São Paulo, SP; the contribution from this park for the regional biodiversity conservation; and analyze its arboreal species in terms of failure risk. For this study, a complete inventory of arboreal vegetation was done. Historically, regional biodiversity conservation was not the initial goal in the park creation. The first introduced trees had area drainage function, with use of exotic arboreal species, such as Eucalyptus and Ligustrum. Nowadays, they represent 16 and $7.29 \%$, respectively, the major percentage of the species classified as high risk of failure, $83.7 \%$. However, late insertion of native species contributed to increase regional biodiversity. Today, Ibirapuera Park has $39.4 \%$ of Brazilian native species. The results of this investigation shows that there is a need of native trees and shrubs continue diversification, so they can contribute for the minimization of diseases, preventing from important factors that cause tree fall. There will also be maintenance of diversity and ecological processes in urban landscape. 
Keywords: Ibirapuera Park, urban forestry, urban park, diversity, high-risk.

\section{INTRODUÇÃO}

O bem estar psicológico propiciado ao homem; a melhoria efeito estético; a sombra para os pedestres e veículos; a proteção e direcionamento do vento; o amortecimento do som, amenização a poluição sonora; a redução do impacto da chuva e seu escorrimento superficial, são benefícios que a arborização proporciona e que podem ser valorados, McPHERSON (2007).

Neste contexto os parques urbanos são espaços que podem promover a melhoria da qualidade ambiental, especialmente quando há uma grande quantidade de espécies arbóreas, como no Parque Ibirapuera, principal área verde de recreação localizada na região sul da cidade de São Paulo.

Existe relação estreita entre risco de queda de uma árvore com tempestades e chuvas fortes e se a árvore está adaptada ao local onde foi plantada e sua integridade estrutural, raízes, caule e parte aérea em condições sanitárias adequadas, USDA (1992), (GILMAN et al., 2006).

Desta forma, objetiva-se com o presente estudo:

1) Discutir como as modificações da configuração da vegetação, desde a criação do parque, influenciaram na composição da vegetação arbórea do Parque Ibirapuera.

2) Discutir a contribuição do Parque Ibirapuera para a conservação da biodiversidade regional.

3) Analisar as espécies arbóreas quanto ao seu risco de queda frente à presença de espécies nativas e exóticas.

\section{MATERIAIS E MÉTODOS}

Para discutir como as modificações da configuração da vegetação, desde a criação do parque, influenciaram na composição da vegetação arbórea, fez-se uma revisão bibliográfica histórica-paisagística. Já para discutir a contribuição do Parque Ibirapuera para a conservação da biodiversidade regional, identificaram-se as espécies arbóreas em nativas brasileiras, nativas do Bioma Mata Atlântica e exóticas do Brasil, utilizando-se dos dados do censo georreferenciado das árvores do Parque Ibirapuera, realizado pela equipe do Centro de Métodos Quantitativos, do Departamento de Ciências Florestais da ESALQ/USP (CMQ/ESALQ/USP) em projeto de pesquisa na linha de políticas públicas

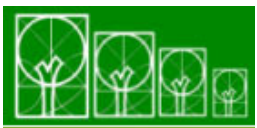

$\mathbf{S} \cdot \mathbf{B} \cdot \mathbf{A} \cdot \mathbf{U}$ Soc. Bras. de Arborização Urbana 
FAPESP/DEPAVE/FEALQ. Todas as árvores foram cadastradas em sistema relacional com variáveis presentes no trabalho de (SILVA FILHO et al., 2002) acrescidas de variáveis presentes na Base SISGAU da Prefeitura de São Paulo, coletadas por meio do uso de computador de mão (tablet) de marca SANSUNG Q1 Ultra. Para obter coordenadas geográficas precisas para todos indivíduos arbóreos foi utilizado equipamento Sistema de Posicionamento Global Topográfico Trimble Pro XT para instalação de 200 marcos geodésicos dos quais serviram de referência para o trabalho de atribuição de coordenadas para as árvores utilizando Estação Total Nikon DTM 320. As espécies arbóreas presentes no Parque foram digitalizadas em fotomapa por meio de suas coordenadas geográficas com auxílio do Sistema de Informações Geográficas Maplnfo Professional, para que fosse possível a visualização espacial das mesmas.

Após a identificação das espécies arbóreas, cada árvore foi avaliada quanto ao risco de queda, utilizando-se a classificação proposta pela USDA (1992). Esta classificação estabelece relações entre a altura da árvore, a altura da primeira ramificação, presença de ramificação em "V", o diâmetro da copa, o diâmetro a altura do peito (DAP) e diâmetro a altura do colo (DAC), ângulo de inclinação, centro gravidade da árvore, e diagnósticos visuais dos danos aparentes (como por exemplo, protuberância, oco, fendas, exsudação de seiva, injúrias mecânicas, presença pragas, entre outros).

Os grupos de indivíduos onde não foi possível a identificação da espécie arbórea ou onde a árvore foi identificada somente pelo gênero foram classificados, para efeito desse estudo, na classe outras, pois sendo identificada como gênero pode haver representantes do gênero de espécies nativas e/ou exóticas.

\section{RESULTADOS E DISCUSSÃO}

Histórico e modificação da composição da vegetação arbórea do Parque Ibirapuera

O Parque Ibirapuera, área do estudo, com seus atuais $1.584 .000 \mathrm{~m}^{2}$, localizado na região sul da cidade de São Paulo, representa a principal área verde da mesma em termos de recreação, oferecendo serviços de lazer, esportes e cultura para usuários da cidade.

Inaugurado em 1954 nas comemorações do IV Centenário da Cidade de São Paulo, teve como responsável pelo projeto arquitetônico, o arquiteto Oscar Niemeyer e o

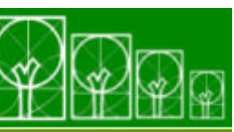

S $\cdot \mathbf{B} \cdot \mathbf{A} \cdot \mathbf{U}$ Soc. Bras. de Arborização Urbana

REVSBAU, Piracicaba - SP, v.6, n.4, p.125-145, 2011 
paisagístico, o engenheiro agrônomo e paisagista Otávio Augusto Teixeira Mendes (SÃO PAULO - SVMA, 2008).

Ibirapuera, de origem tupi-guarani Ypy-ra-ouêra significa "árvore apodrecida" ou "árvore podre" (MIGLIONICO, 2007), o que remete à área original e a história do próprio parque que passa por intensas transformações até chegar à composição que atualmente presenciamos.

Área de várzea, com passagem dos córregos Sapateiro e Boa Vista (ou Caaguaçu), era conhecida como região alagadiça, portanto de difícil ocupação para fins que não fossem de pastagem. Serviu como passagem para boiadas com destino ao Matadouro e área de pastagem para aqueles que aguardavam o abate, fato ocorrido desde o início da colonização paulistana (KLIASS, 1993; OLIVEIRA, 2003; MIGLIONICO, 2007). Originalmente, a área era composta de vegetação de capoeira com poucas árvores esparsas (Figura 1), sendo alagada em determinadas épocas do ano (MIGLIONICO, 2007).

Sob gestão municipal de Pires do Rio, em 1926 surgem as primeiras idéias da possibilidade de transformar a área do Ibirapuera em um grande parque público. Nesse mesmo ano, influenciado pela questão higienista relacionado a pântanos e áreas alagadiças ocorre a efetiva ocupação e higienização da área do Ibirapuera, visto que áreas nessas condições eram consideradas focos de doenças (OLIVEIRA, 2003).

Assim, Manuel Lopes de Oliveira, vulgo "Manequinho Lopes", inicia o trabalho de drenagem da área com o uso de eucaliptos, amplamente difundido na Europa. Foram utilizados eucaliptos australianos, exemplares ainda encontrados atualmente no parque (MIGLIONICO, 2007). Segundo Oliveira (2003, p.75), "Os pensamentos a respeito das propriedades sanitárias do eucalipto eram muitas e, em grande parte, exageradas". Desta forma, Oliveira (2003) ainda observa que não há comprovações de que o plantio de eucaliptos por si só tenham drenado a área e de que o paisagista da época, Oliveira Filho, possa ter implantado, simultaneamente, sistemas de drenagem superficiais. 
Figura 1. Zonas pantanosas na área central, em direção do atual prédio do DETRAN, década de 1930. (acervo Histórico do Instituto Biológico, apud MIGLIONICO, 2007, p.89)

Figure 1. Wetlands in the central area in the direction of the current building, DETRAN, 1930s. (Historical Collection of the Biological Institute, cited in Miglionico, 2007, p.89)

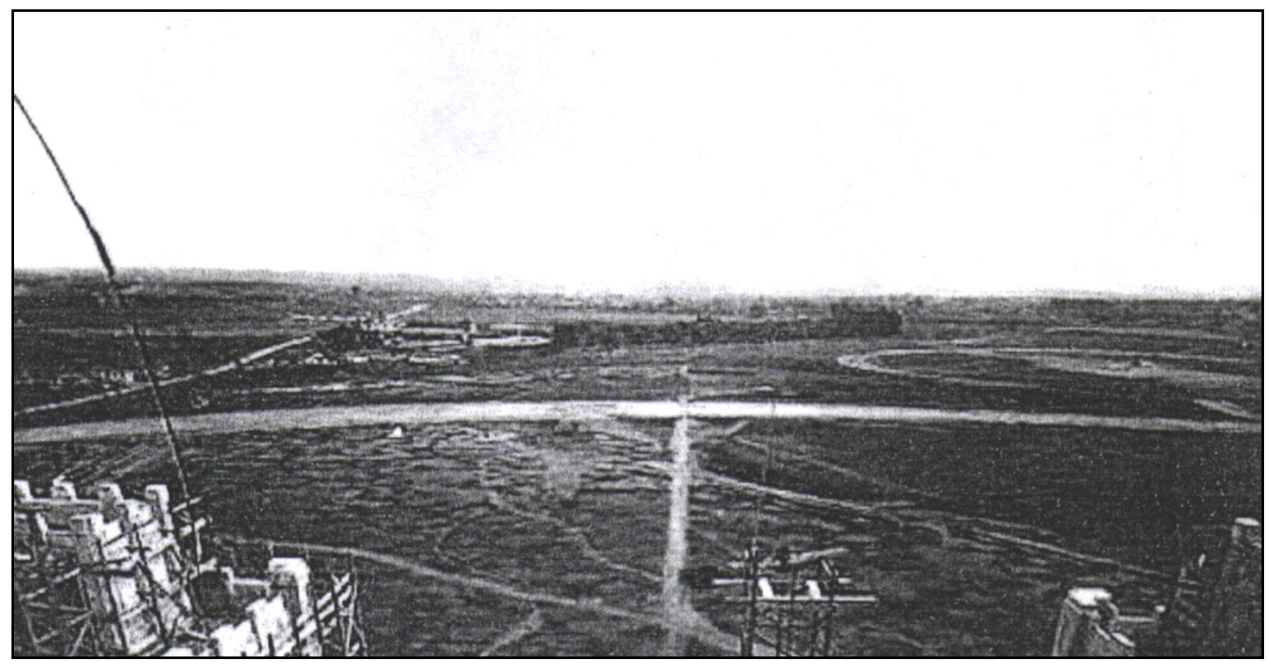

Os eucaliptos, além de contribuírem na drenagem da área, forneceram sombra para que outras espécies pudessem se desenvolver, ocorrendo a disseminação de inúmeras espécies nacionais e estrangeiras (OLIVEIRA, 2003). Seu plantio não foi aleatório:

"A plantação dos eucaliptos, em grande número sob a lógica da eficiência botânica, ao olhar mais cuidadoso, demonstra respeitar linhas diretoras, desenhos que permitissem o aproveitamento mais racional das mudas e a melhor ocupação da área. A lógica da implantação dos eucaliptos pode ser percebida a partir de uma visão mais acurada sobre o existente. Há um número maciço de árvores, próximas e relacionadas por linhas geométricas claras. A plantação não se deu a esmo ou de modo aleatório, teve uma preocupação racionalista de resolver um problema da melhor forma possível para o momento, além de contribuir para a construção da paisagem com a marcação de grandes massas de vegetação, balizando o local, construindo os seus primeiros referencias verticais." (OLIVEIRA, 2003, p.78) 
O projeto paisagístico do Parque Ibirapuera passou por uma série de propostas, desde Dierberger a Burle Marx e Otavio Augusto Teixeira Mendes, sendo executado o projeto do último. Oliveira (2003) coloca que a forma de composição paisagística do parque não visava à representação da "natureza intocada", mas de reverenciar o "progresso" de São Paulo. De qualquer forma, observa-se nesta época uma tendência nos projetos paisagísticos o uso de espécies nativas, o que se comprova no censo georreferenciado do CMQ/ ESALQ/USP, como pode ser observado a seguir.

Quanto a espécies, destacamos o interesse pelas espécies florestais nativas:

"Muitas espécies foram plantadas destacando-se árvores representativas brasileiras, pela nobreza das madeiras associadas a uma composição com a flora regional. Concebeu um bosque atrás do lago a partir de plantas existentes complementadas por árvores autóctones, além plantadas, como o carvalho brasileiro, pau-brasil, guatambu, cedro-rosa, e jatobá, plantadas em substituição às retiradas em outros locais." (MIGLIONICO, 2007, p.159)

Atualmente, podem ser encontradas no parque, graças ao trabalho do viveiro de Manequinho Lopes, espécies como Pau-Brasil, Pau-Ferro, Pau-Jacaré, Sibipiruna, Tipuana e Ipê (MIGLIONICO, 2007). Muitos dos remanescentes de árvores e arbustos são remanescentes do projeto paisagístico de Otavio Augusto Teixeira Mendes como figueirabenjamim, chicha, carvalho brasileiro, ipê-rosa, bosques de jaqueira e guapuruvus, além de conjuntos de sete capotes e araribá. Encontra-se também outras espécies como pau-ferro, banyan-da-índia, paineira e tamareira-das-canárias.

\section{Contribuição do Parque Ibirapuera para a conservação da biodiversidade regional}

A preocupação com conservação da diversidade biológica, entendida como a "variabilidade de organismos vivos de todas as origens, compreendendo, dentre outros, os ecossistemas terrestres, marinhos e outros ecossistemas aquáticos e os complexos ecológicos de que fazem parte, compreendendo ainda a diversidade dentro de espécies, entre espécies e de ecossistemas" (BRASIL, 2000), deve ser estendida para as áreas urbanas.

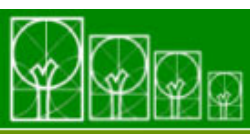

$\mathbf{S} \cdot \mathbf{B} \cdot \mathbf{A} \cdot \mathbf{U}$ Soc. Bras. de Arborização Urbana 
Isso porque, entre outros fatores, há um aumento na fragmentação de diversos ecossistemas brasileiros, principalmente a Mata Atlântica. Por conseguinte, essa fragmentação tem levado a uma drástica redução na diversidade biológica, seja imediatamente, através da perda da área, ou a longo prazo, através dos efeitos do isolamento (METZGER, 2004).

A existência de uma área verde urbana como o Parque lbirapuera, sendo abrigo de espécies arbóreas, pode aumentar a capacidade dessa paisagem urbana de facilitar os fluxos biológicos, contribuindo para a conservação genética da biodiversidade, desde que elas contenham as árvores nativas.

Desta forma, para avaliar se a vegetação presente no Parque Ibirapuera é um fragmento de vegetação que efetivamente contribua para a conservação da biodiversidade, faz-se necessário saber quais são a distribuição e a quantidade das espécies arbóreas nativas. Estas espécies favorecem a conservação genética não somente de indivíduos arbóreos no Parque Ibirapuera, mas também de regiões circunvizinhas. A diversidade no genótipo das espécies nativas presentes nesta flora urbana permitirá a vivência das espécies vegetais utilizadas por diversas gerações, diminuindo o risco do surgimento de endogamia e deriva genética, contribuindo para a perpetuação de espécies e impedindo, desta forma, as extinções futuras.

De acordo com o censo georreferenciado do CMQ/ESALQ/USP das árvores do Parque Ibirapuera, mostra que há 15.055 árvores no parque. Entre essas, verifica-se que 5.934 indivíduos (Tabela 1), ou 39,4\% pertence a espécies nativas brasileiras (Figura 2).

Tabela 1. Número e espécies de árvores encontradas no Parque Ibirapuera, com a respectiva classificação

Table 1. Number of trees species found in Ibirapuera Park with respective classification

\begin{tabular}{llll}
\hline CLASSIFICAÇÃO & $\begin{array}{l}\text { NÚMERO } \\
\text { ÁRVORES }\end{array}$ & $\begin{array}{l}\text { DE NÚMERO } \\
\text { ESPÉCIES }\end{array}$ & DE \\
\hline Nativas Brasileiras & 5.934 & 168 \\
\hline Exóticas do Brasil & 8.668 & 161 \\
\hline Outras & 453 & 27 \\
\hline TOTAL & 15.055 & 356 \\
\hline
\end{tabular}


Figura 2. Porcentagem de árvores de acordo com a classificação (exóticas, nativas e outras) encontradas no Parque Ibirapuera

Figure 2. Percentage of trees according with the classification (exotic, native and others) found in Ibirapuera Park

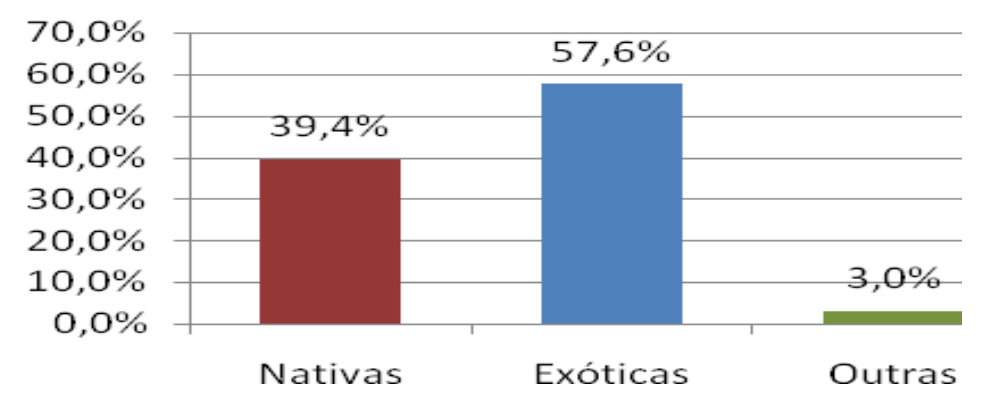

Já 8.668 indivíduos, ou 57,6\% (Figura 2) são representantes de espécies exóticas do Brasil.

A principal causa para essa introdução de espécies de árvores exóticas, em especial os eucaliptos, no processo de construção do Parque Ibirapuera, foi para drenagem da área que inicialmente se encontrava bastante alagadiça (MIGLIONICO, 2007; OLIVEIRA, 2003).

Das 356 espécies encontradas no Parque Ibirapuera, 168 ou 47,2\% são nativas brasileiras e 161 ou 45,2\% são exóticas do Brasil (Figura 3).

Figura 3. Porcentagem de espécies arbóreas encontradas no Parque Ibirapuera Figure 3. Tree species percentage found in Ibirapuera Park

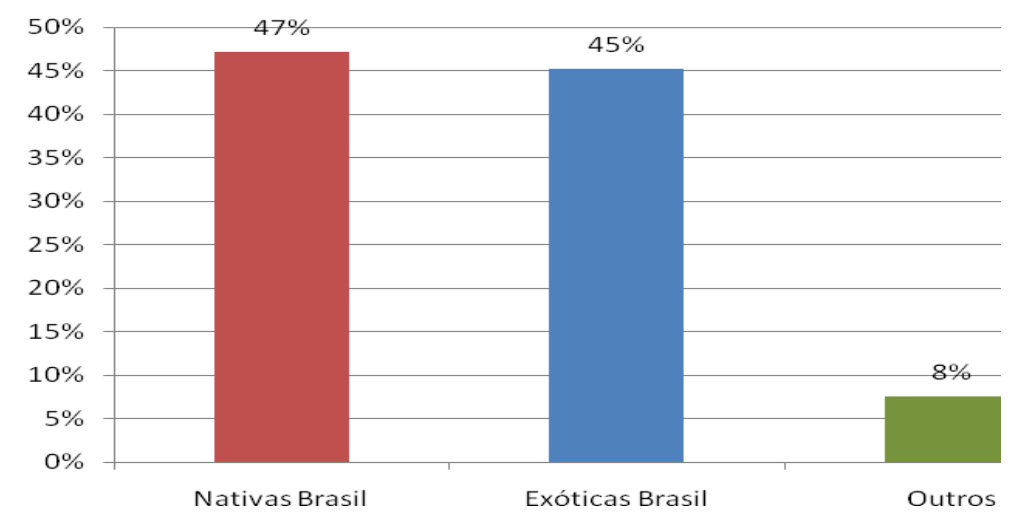

Pode-se observar que mesmo as espécies exóticas tendo maior número de indivíduos (8.668 indivíduos) que as espécies nativas (5.934 indivíduos), há um maior número de espécies nativas (168 espécies) em relação às espécies exóticas (161 espécies).

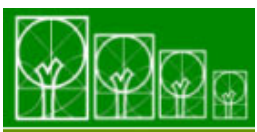


Mesmo as espécies nativas representando 39,4\% árvores do Parque Ibirapuera, essa possuem maior número de espécies (47,2\%), como visto na Figura 3 . A maior diversidade das espécies nativas é um importante fator para considerar o Parque Ibirapuera como local potencial de conservação da biodiversidade de espécies arbóreas brasileiras.

Em relação às espécies nativas brasileiras do parque, notamos na Figura 4 que 5.934 indivíduos (97,1\%) pertencem ao Bioma Mata Atlântica, sendo 170 indivíduos (2,9\%) são espécies nativas brasileiras provenientes de outro bioma brasileiro que não o da região da Mata Atlântica. Observa-se, assim, que a grande maioria das espécies identificadas como nativas do Brasil são também pertencentes a espécies do contexto regional na qual se insere o parque, o que se entende como um dado que pode contribuir para a conservação da biodiversidade regional.

É importante lembrar que a introdução de plantas exóticas invasoras é considerada atualmente a segunda maior ameaça mundial à biodiversidade, perdendo apenas para a destruição de habitats pela exploração humana direta (ZILLER, 2000). Algumas espécies exóticas presentes no parque são citadas como invasoras em outras regiões como: Morus nigra (amoreira), Melia azedarach (santa-bárbara), Artocarpus heterophyllus (jaqueira), Mangifera indica (mangueira), Coffea arábica (cafeeiro), Eucalyptus sp (eucalipto), Spathodea campanulata (espatodia), e Pinus ellioti (Pinus).

A utilização de espécies exóticas pode-se constituir em risco para a conservação da biodiversidade, sendo estas responsáveis por processos de invasão biológica.

Figura 5. Foto Satélite do Parque do Ibirapuera

Figure 5. Ibirapuera Park`s photo satellite

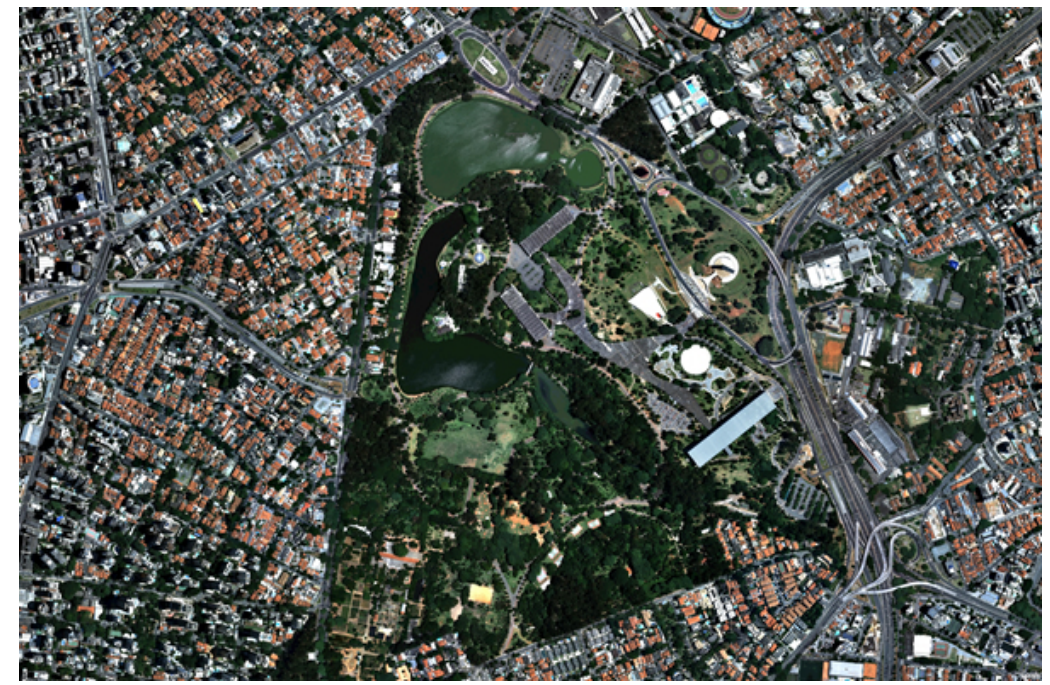

Fonte: Google Earth 
Figura 6. Árvores pertencentes a espécies exóticas do Brasil no Parque do lbirapuera Figure 6. Exotic trees in Ibirapuera Park

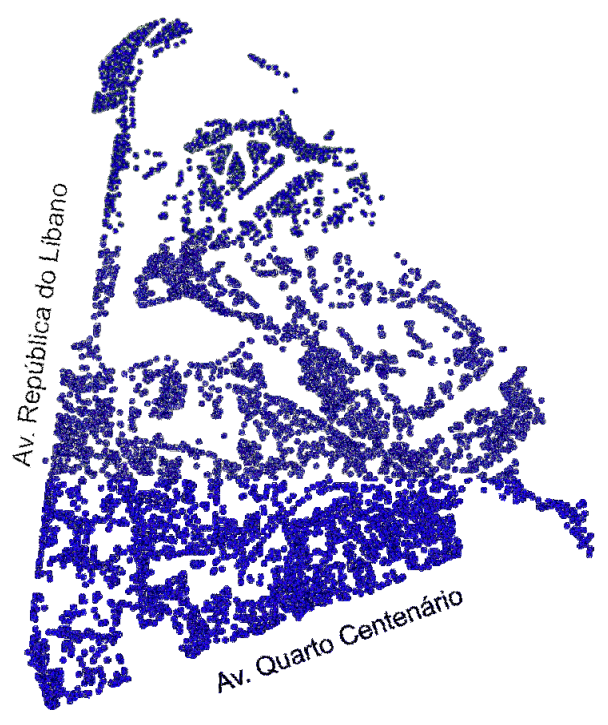

Figura 7. Árvores pertencentes a espécies nativas brasileiras no Parque do lbirapuera Figure 7. Native trees in Ibirapuera Park

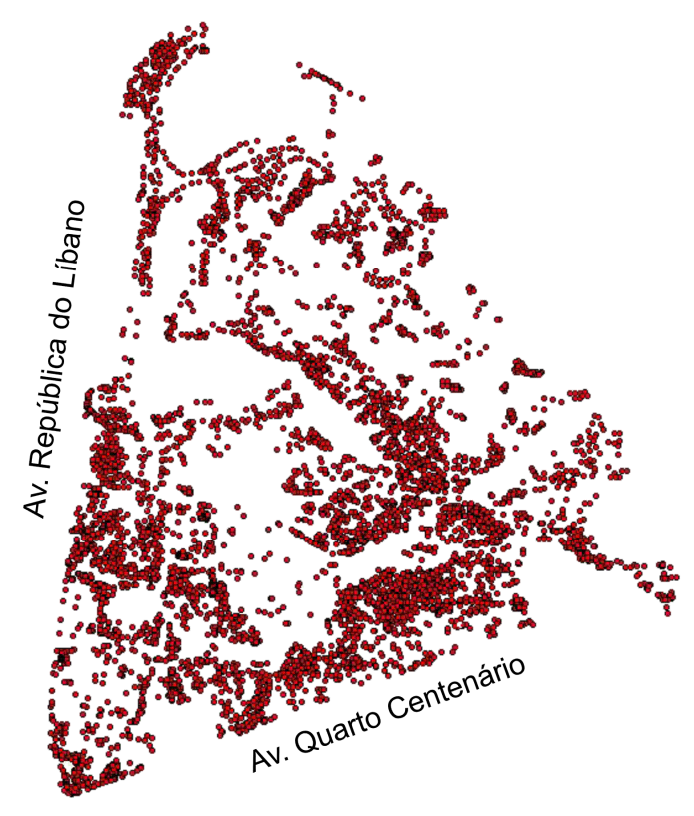

Observa-se nas Figuras 6 e 7 que há árvores de espécies tanto nativas brasileira quanto exóticas em toda a extensão do parque, com alguns pontos de concentração. No caso de espécies exóticas destacam-se blocos, que provavelmente são os mesmos 
implantados antes da inauguração do parque. Como afirma Oliveira (2003, p.78), "grandes massas de vegetação, balizando o local, constituindo os seus primeiros referenciais verticais" e resolvendo problemas de drenagem, e possivelmente, por este motivo, as aglomerações encontram-se em diferentes regiões do Parque.

Nota-se que há blocos de árvores exóticas nas bordas do parque - da Av. República do Líbano, Av. Quarto Centenário, beirando a Rua Manuel da Nóbrega. Nessas mesmas massas podemos observar aglomerações de árvores de espécies nativas, que formam uma espécie de sub-bosque, contribuindo para a criação de uma barreira visual natural, que impede a visão do entorno bastante urbanizado, exercendo assim, um importante elemento paisagístico do parque.

No censo do georreferenciado do CMQ/ESALQ/USP também constam a área basal e área de cobertura de copa das árvores, que foram analisados na Figura 8 a fim de determinar a real contribuição das espécies florestais nativas para a conservação da biodiversidade.

Figura 8. Porcentagem de cobertura de copa, de área basal, número de indivíduos e número de espécies das espécies nativas e exóticas do Brasil

Figure 8. Percentage of canopy cover, basal area, number of individuals and number of species of native and exotic species in Brazil

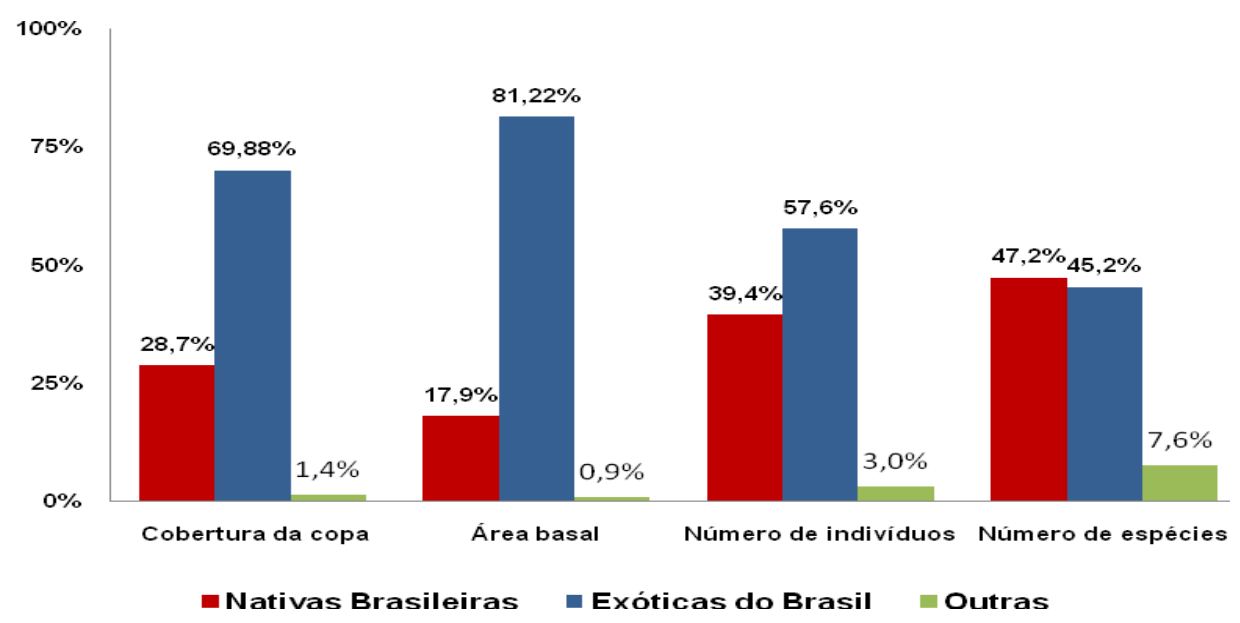

A partir desses dados podemos perceber que as espécies exóticas além de serem representadas por um maior número do que as espécies nativas, estes também apresentam maior porte, observado pela grande área basal e cobertura de copa. 
A idéia de que a fauna, para obter alimento, depende direta ou indiretamente da vegetação, é um dos princípios ecológicos dos mais importantes, não necessitando de comprovação, sendo parte integrante das noções elementares de ecologia (FIRKOWSKI, 1991). Conseqüentemente, a vegetação arbórea do Parque Ibirapuera é um importante recurso para a fauna local.

É sabido que o conhecimento da área basal é de fundamental importância para estimar os modelos de crescimento e produção, assim como no cálculo de volume/ha, dando idéia de estoque de matéria na floresta. Quanto maior a matéria da floresta, estimada pela área basal, maior também será sua contribuição para a manutenção dos processos ecológicos da comunidade, uma vez que, entre outros, há um maior volume de recursos para a fauna.

Já a importância da área de cobertura de copa deve-se ao fato de que as copas das árvores abrigam a maior parte da vida das florestas tropicais. Isso porque é o local de abrigo de um grande número de plantas, como as lianas e epífitas; e de fauna, desde invertebrados como aranhas e insetos, mas principalmente a avifauna.

As copas das árvores são importantes nichos para avifauna, pois estes animais as utilizam para apanhar alimentos, para a nidificação e abrigo. Diante disso, quanto maior for a cobertura de copa, maior será a disponibilidade de recurso alimentar para a fauna silvestre, contribuindo desta forma, para a conservação da biodiversidade.

Do número total das espécies presentes no parque, 47,2 \% das espécies é nativa do Brasil. No entanto, a cobertura de copa e área basal dessas espécies, respectivamente, são $28,7 \%$ e 17,9\%, o que representam, atualmente, uma proporção menor de contribuição para manutenção dos processos ecológicos (Figura 8).

Já as espécies exóticas possuem uma área de copa (71,3\%) e área basal (82,1\%) maior do que as nativas. Isso se deve ao fato de que as espécies exóticas apresentarem os maiores indivíduos, uma vez que são os indivíduos mais antigos, implantados há mais de 60 anos, inicialmente para fins de estabilização do terreno (drenagem).

Do ponto de vista da conservação da biodiversidade vegetal, as espécies exóticas não são tão interessantes, pois, como visto anteriormente, pode competir por recursos hídricos, por nutrientes minerais no solo e por luminosidade, ou até mesmo ter efeitos alopáticos que podem comprometer o desenvolvimento das espécies nativas.

Todavia, em relação à conservação da fauna, algumas espécies de árvores exóticas podem ser úteis, pois além de oferecerem recursos alimentares para a fauna, através de

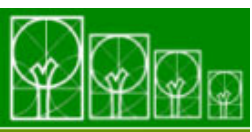

$\mathbf{S} \cdot \mathbf{B} \cdot \mathbf{A} \cdot \mathbf{U}$ Soc. Bras. de Arborização Urbana 
seus frutos, podem contribuir da mesma forma que as espécies nativas com relação ao uso como abrigo e nidificação.

\section{Espécies arbóreas classificadas com risco de queda alto no Parque Ibirapuera}

Considera-se uma árvore em péssimo estado, ou seja, com alto risco de queda, aquela em estado avançado e irreversível de declínio, com ataque ou dano intenso de pragas, doenças, deficiências, prejudicando a função do individuo na arborização e causando morte do vegetal (SILVA FILHO et.al., 2002).

No Parque Ibirapuera existem 1.632 árvores classificadas como sendo de risco de queda alto (Tabela 2), sendo que entre elas 83,7\% são espécies exóticas (Figura 8).

Tabela 2. Número de árvores e porcentagem, entre espécies exóticas e nativas, classificada com Risco de Queda Alto

Table 2. Percentage and numbers of exotic and native species, classificated with high risk of falling

\section{CLASSIFICAÇÃO DAS ESPÉCIES № DE ÁRVORES PORCENTAGEM}

\begin{tabular}{lcc}
\hline Nativas & 215 & $13,2 \%$ \\
Exóticas & 1.366 & $83,7 \%$ \\
Outras & 51 & $3,1 \%$ \\
\hline Total de árvores com risco de queda alto & 1.632 & $100 \%$ \\
\hline
\end{tabular}

Já na Tabela 3, que mostra as dez espécies/gêneros mais abundantes classificadas com risco de queda alto no Parque lbirapuera, nota-se que estas dez espécies representam $40,6 \%$ do total de indivíduos presentes no parque, com domínio de espécies do gênero Eucalyptus e da espécie Ligustrum lucidum (alfeneiro). 
Tabela 3. As dez espécies com "risco de queda alto" mais abundantes no Parque Ibirapuera Table 3. Ten species with high risk of falling

\begin{tabular}{|c|c|c|}
\hline ESPÉCIES/GÊNERO & NOME COMUM & NÚMERO DE PORCENTAGEM CLASSIFICAÇÃO \\
\hline MAIS ABUNDANTES & & INDIVÍDUOS \\
\hline
\end{tabular}

\begin{tabular}{ccccc}
\hline Eucalyptus $s p$ & Eucaliptus & 2.413 & 16 & Exótica \\
Ligustrum lucidum & Alfeneiro & 1.099 & 7,29 & Exótica \\
Eugenia uniflora & Pitangueira & 453 & 3,01 & Nativa \\
Tipuana tipu & Tipuana & 388 & 2,58 & Exótica \\
Holocalix balansae & Alecrim-de- & 323 & 2,14 & Nativa \\
& campinas & & & \\
Aglaia odorata & Aglaia (falsa murta) & 304 & 2,02 & Exótica \\
Ceiba speciosa & Paineira & 302 & 2,00 & Nativa \\
Tabebuia pentaphylla & Ipê de el salvador & 287 & 1,90 & Exótica \\
Archontophoenix & Seafórtia & 279 & 1,85 & Exótica \\
cunninghamiana & (palmeira) & & & Nativa \\
Centrolobium & Arariba rosa & 265 & 1,76 & \\
tomentosum & & & & \\
\hline
\end{tabular}

O grande numero de indivíduos de mesma espécie, como Eucaliptus sp e Alfeneiro pode ser uma das causas do risco de queda alto, favorecendo o aumento do ataque de insetos e doenças (LACAN e MCBRIDE, 2008).

Analisando o levantamento de árvores (Tabela 3) no Parque Ibirapuera, assim como em grande parte arborização viária brasileira, em ambos os casos prevalecem a homogeneidade de espécies, o que aumenta segundo Silva Filho e Bortoleto (2005), a vulnerabilidade em relação a pragas e doenças.

Para a implantação de um parque urbano, como o Parque Ibirapuera, há necessidade de uma diversificação biológica de árvores e arbustos com espécies florestais nativas, pois além de contribuir para a minimização de pragas e doenças vegetais, haverá também a manutenção da diversidade e dos processos ecológicos na paisagem urbana.

Certamente o histórico de criação do parque favorece a manutenção de diversidade de espécies nativas, visto que em sua época de implantação predominava a idéia do uso de espécies brasileiras. Como afirma Oliveira (2003, p.336), "os espaços verdes construídos, o jardim, o parque, todas essas manifestações paisagísticas, das primeiras décadas do século 
aos anos 50, foram objetos das mais profundas revisões e preocupações no sentido de torná-los brasileiros".

Outro dado importante é o grande número de espécies exóticas com risco alto de queda. Como visto na Figura 8, as espécies exóticas possuem maior porcentagem de área basal, o que pode implicar na queda de árvores com considerável volume, tornando a situação de risco de queda ainda mais sério, já que envolve um parque com grande número de visitantes. Deve ser considerado também que tais árvores produzem um efeito paisagístico importante ao estruturar os cenários dos visitantes dentro do Parque por meio da obstrução da visão de prédios e demais elementos da cidade.

\section{CONCLUSÃO}

O Parque Ibirapuera, além de um importante espaço de recreação, esportes, lazer e cultura, representa também relevante colaboração para a conservação da biodiversidade. Apesar de inicialmente existir maior preocupação em promover a drenagem da área por questões sanitárias com o uso de árvores exóticas como do gênero Eucaliptus, ocorreu, posteriormente o interesse no uso de espécies nativas brasileiras, o que contribui para 0 aumento da biodiversidade regional.

Com os dados do censo georreferenciado, e posterior identificação das espécies arbóreas, verificou-se que $39,4 \%$ das árvores eram espécies nativas, além de ter uma variedade maior de espécies nativas em relação às exóticas.

A presença de espécies nativas do Bioma Mata Atlântica, é importante no contexto de conservação da biodiversidade vegetal regional, visto que mesmo nativas do Brasil, podem representar espécies exóticas para o contexto regional do parque.

A avaliação realizada neste artigo pode ser útil para o planejamento de parques urbanos, seja na escolha das melhores espécies arbóreas para a conservação da biodiversidade, no caso do Parque Ibirapuera as espécies nativas do Bioma Mata Atlântica, ou nas futuras tomadas de ações quanto ao manejo da vegetação nos parques.

Isso porque ao se analisar as espécies com risco de queda alto, verifica-se que 83,7 \% uma maior quantidade de espécies exóticas, as mais antigas do Parque, podendo implicar na queda de árvores de grande porte, isto é, maiores riscos, agravados pelo grande número de visitantes do parque. No entanto, uma maior quantidade de espécies exóticas com risco de queda alto, poderiam, em longo prazo, favorecer a conservação da

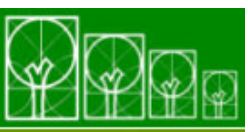

$\mathbf{S} \cdot \mathbf{B} \cdot \mathbf{A} \cdot \mathbf{U}$ Soc. Bras. de Arborização Urbana 
biodiversidade, seja por meio da permanência de um maior número e variedade de espécies nativas, ou pela substituição das espécies com risco de queda alto, por espécies nativas.

Como visto nesta pesquisa, o Parque Ibirapuera, mesmo com a sua vegetação formando um fragmento florestal pequeno, têm uma importante função ecológica para a conservação da fauna, uma vez que produz recursos alimentares, atrai e permiti a sobrevivência da fauna, principalmente avifauna.

Sugere-se no planejamento e manutenção da vegetação do Parque Ibirapuera o enriquecimento com espécies florestais nativas, possibilitando um aumento potencial dessa área para a conservação da biodiversidade, contribuindo inclusive no fluxo genético de espécies por meio da dispersão de sementes em relação a áreas verdes do entorno.

Dessa maneira, para a implantação de um parque urbano, há necessidade de uma diversificação biológica de árvores e arbustos com espécies florestais nativas, pois além de contribuir para a minimização de pragas e doenças vegetais, haverá também a manutenção da diversidade e dos processos ecológicos na paisagem urbana.

\section{REFERÊNCIAS BIBLIOGRÁFICAS}

BRASIL. Lei n.4771, de 15 de setembro de 1965. Institui o novo Código Florestal. Disponível em: < http://www.planalto.gov.br/ccivil_03/LEIS/L4771.htm>. Acesso em: 26 out 2008.

BRASIL. Lei n.9985, de 18 de julho de 2000. Regulamenta o art. 225, § 1ํㅡㄹ incisos I, II, III e VII da Constituição Federal, institui o Sistema Nacional de Unidades de Conservação da Natureza e dá outras providências. Disponível em: <http://www.planalto.gov.br/ccivil_03/leis/19985.htm>. Acesso em: 6 out 2008.

CARVALHO, P. E. R. Espécies arbóreas brasileiras. Brasília, DF: Embrapa Informação Tecnológica; Colombo,PR: Embrapa Florestas, 2003. v.1, 1039 p.

IUCN - UNIÃO INTERNACIONAL PARA A CONSERVAÇÃO DA NATUREZA. Guidelines for protected areas management categories. Gland, 1994. 29 p. 
FIRKOWSKI, C. O hábitat para a fauna: manipulações em micro escala. Floresta, Curitiba. v. 21, n. 12, p. 27-43, 1991.

KLIASS, R. G. Parques Urbanos de São Paulo e sua evolução na cidade. São Paulo: Pini, 1993. 211p.

LACAN, I.; MCBRIDE, J. R.. Pest Vulnerability Matrix (PVM): A graphic model for assessing the interaction between tree species diversity and urban forest susceptibility to insects and urban forest susceptibility to insects and diseases. Urban Forestry and Urban Greening. v. 7, n. 4, p. 291-300,2008.

LORENZI, H. Árvores brasileiras: Manual de identificação e cultivo de plantas arbóreas nativas do Brasil. V.1. Nova Odessa, SP: Plantarum, 2002. 384p.

LORENZI, H. Árvores brasileiras: Manual de identificação e cultivo de plantas arbóreas nativas do Brasil. V.2. Nova Odessa. SP: Plantarum, 1999. 384p.

METZGER, P. M. Delineamento de experimentos numa perspectiva de ecologia da paisagem. In: CULLEN Jr. L.C.; VALLADARES-PADUA, C. Métodos de estudos em biologia da conservação \& manejo da vida silvestre. Curitiba: UFPR, 2004. p. 539-553.

MIGLIONICO, R. I. Parque do Ibirapuera: um ícone da paisagem paulistana. Dissertação de Doutorado, Faculdade de Arquitetura e Urbanismo da Universidade de São Paulo, FAUUSP, 2007. 288p.

OLIVEIRA, F. L. de. Projetos para o Parque do Ibirapuera: de Manequinho Lopes a Niemeyer (1926-1954). Dissertação (Mestrado em Arquitetura e Urbanismo) - Escola de Engenharia de São Carlos da Universidade de São Paulo. São Carlos, 2003. 371p.

PARKER, I. M.; SIMBERLOFF, D.; LONSDALE, W. M.; GOODELL, K.; WONHAM, M.; KAREIVA, P. M.; WILLIAMSON, M. H.; VONHOLLE, B.; MOYLE, P. B.; BYRES, J. E.; GOLDWASSER, L.. Impact: toward a framework for understanding the ecological effects of invaders. Biological Invasions 1. p. 3-19, 1999. 
PEGADO, C. M. A.; ANDRADE, L. A.; FELIX, L. P. et al. Efeitos da invasão biológica de algaroba: Prosopis juliflora (Sw.) DC. sobre a composição e a estrutura do estrato arbustivo-arbóreo da caatinga no Município de Monteiro, PB, Brasil. Acta Botânica Brasílica, v.20, p.887-898, 2006.

PIVETTA, K. F. L.; SILVA FILHO, D. F. Arborização Urbana. Jaboticabal, SP, 2002. 74p. (Boletim Acadêmico - Série Arborização Urbana)

SÂO PAULO (Cidade). Secretaria Municipal do Verde e do Meio Ambiente. Trilha do Ibirabuera. Disponível em:

<http://www.prodam.sp.gov.br/svma/educacao_amb/edu_ambiental/trilhas/trilha_ibira/trilhad oibira.htm>. Acesso em: 18 out. 2008.

SILVA FILHO, D. F.; BORTOLETO, S. Uso de Indicadores de Diversidade na Definição de Plano de Manejo da Arborização Viária de Águas de São Pedro - SP1. Revista Árvore, Viçosa, MG, v.29, n.6, p. 973-982, 2005.

SILVA FILHO, D. F.; CÉSAR, P. P. U.; ALMEIDA, J. B. S. A.; PIVETTA, K. F. L.; FERRAUDO, A. S. Banco de dados relacional para cadastro, avaliação e manejo da arborização em vias públicas. Revista Árvore, Viçosa, v.26, n.5, p.629-642, set-out, 2002.

TAIZ, L.; ZEIGER, E. Fisiologia Vegetal.3. ed. Porto Alegre, RS: Artmed, 2004. 719 p.

USDA - United States Department of Agriculture. Urban Tree Risk Management: A Community Guide to Program Design and Implementation. St. Paul, MN: USDA Forest Service, 1992.

WILLIAMSON, M. Biological invasions. London: Chapman \& Hall, 1996.

ZANCHETTA, D.; DINIZ, F. V. Estudo da contaminação biológica por Pinus spp. em três diferentes áreas na Estação Ecológica de Itirapina (SP, Brasil). Revista do Instituto Florestal, São Paulo, v. 18, n. único, p. 1-14, dez. 2006. 
ZILLER, S. R. A Estepe Gramíneo-Lenhosa no segundo planalto do Paraná: diagnóstico ambiental com enfoque à contaminação biológica. Dissertação (Doutorado em Ciências Agrárias) - Universidade Federal do Paraná. Curitiba, 2000. 268 p.

ZILLER, S. R. Opinião. Revista Ciência Hoje, São Paulo, v. 30, n. 178, p. 78, 2001. 